\title{
SMART CITY KUTAI KARTANEGARA DENGAN PENDEKATAN FRAMEWORK CITIASIA: SEBUAH KAJIAN ANALISIS
}

\author{
Indah Fitri Astuti ${ }^{1)}$ dan Dedy Cahyadi ${ }^{2)}$ \\ ${ }^{1,2}$ Jurusan Ilmu Komputer, Fakultas Ilmu Komputer dan Teknologi Informasi, Universitas Mulawarman \\ Jalan Penajam, Kampus Gunung Kelua, Samarinda, 75000 \\ E-mail : indahfitriastuti@unmul.ac.id ${ }^{1)}$,dedy.cahyadi@unmul.ac.id ${ }^{2)}$
}

\begin{abstract}
ABSTRAK
Kabupaten Kutai Kartanegara di provinsi Kalimantan Timur adalah salah satu dari 25 kabupaten/kota yang mendapat kesempatan untuk mulai mengembangkan Gerakan 100 Smart City yang dicanangkan pada Smart City Summit 2017 di Makassar. Rencana Pembangunan Jangka Menengah Daerah (RJPMD) 2016-2021 kemudian memuat perencanaan pembangunan Samrt City yang disepakati dengan istilah Smart Regency Kutai Kartanegara dengan visi terwujudnya masyarakat kabupaten Kutai Kartanegara yang cerdas dengan sektor pertanian dan pariwisata sebagai penggerak utama yang didukung oleh teknologi informasi. Tujuan penelitian ini adalah untuk menyusun analisis Smart Regency Kutai Kartanegara.

Metode analisis Smart Regency Kutai Kartanegara disusun dengan menggunakan pendekatan kerangka kerja Citiasia. Model Citiasia mempromosikan kemajuan bangsa dengan menyediakan solusi kota pintar yang menggabungkan model yang akurat dan kuat dengan dukungan teknologi canggih dan mudah digunakan. Terdapat enam aspek cerdas yang akan dianalisis dan dibangun, yaitu smart governance, smart branding, smart economy, smart living, smart society, dan smart environment.

Penelitian menghasilkan dokumen analisis Smart Regency yang telah dilengkapi dengan analisis gap antar aspek cerdas, analisis pembangunan Smart Regency, sasaran, arah kebijakan, dan analisis kesiapan daerah.
\end{abstract}

Kata Kunci: analisis, smart city, kutai kartanegara

\section{PENDAHULUAN}

Gagasan Gerakan Menuju 100 smart city muncul dari berbagai kalangan, yaitu dari pemerintahan (Departemen Dalam Negeri; Kementerian Kementerian Komunikasi dan Informatika; Pekerjaan Umum dan Perumahan Rakyat; Badan Perencanaan Pembangunan Nasional; Kantor Staf Kepresidenan), beberapa tim ahli dari akademisi dan praktisi (UI; ITB; UMN; Perbanas; Citiasia; dan institusi lainnya) dan perwaklian dari beberapa perusahaan (seperti Siemens; Indosat Ooredoo Business; Lintasarta; dan Kompas Gramedia). Gerakan ini resmi diluncurkan pada acara Indonesia Smart City Summit 2017 di Makassar pada 22-23 Mei 2017 bersamaan dengan penandatanganan MoU antara Pemerintah dengan 25 Kepala Daerah yang daerahnya telah terpilih untuk menjadi Pilot Project Smart City di tahun 2017 ini.

Kabupaten Kutai Kartanegara (Kukar) merupakan 1 dari 25 daerah yang telah lolos seleksi dan terpilih untuk melaksanakan program kerja dari Gerakan 100 Smart City (Surat Pemberitahuan Nomor 26.KOMINFO/DJAl/AI.01,05/05/2017). Kabupaten Kutai Kartanegara (Kab. Kukar) dapat memenuhi beberapa hal yang dijadikan parameter penilaian dalam proses assessment Smart City, yaitu visi, regulasi, SDM, serta potensi daerah. Terdapat beberapa faktor pendukung yang dapat mendorong Kabupaten dengan luasan terbesar ke-2 di Kalimantan Timur dalam memenuhi parameter Smart City, antara lain: tempat sejarah awal pola pemerintahan (kerajaan) di Indonesia; merupakan Kabupaten di Kaltim dengan PDRB tertinggi; memiliki tujuan wisata yang relatif lengkap; memiliki sumber daya alam yang beragam; terletak di daerah aliran sungai Mahakam dan Delta Mahakam yang merupakan jalur transportasi dan perekonomian di Provinsi Kalimantan Timur.

Visi pembangunan daerah dalam RPJMD Kabupaten Kutai Kartanegara Tahun 2016-2021 merupakan penjabaran dari visi Kepala Daerah dan Wakil Kepala Daerah terpilih, yang mendukung pengembangan smart city. Visi menggambarkan arah pembangunan atau kondisi masa depan daerah yang ingin dicapai (desired future) dalam masa jabatan selama 5 (lima) tahun. Dengan mempertimbangkan potensi, kondisi, permasalahan, tantangan dan peluang yang ada di Kabupaten Kutai Kartanegara, visi yang hendak dicapai dalam periode 2016-2021 adalah "Terwujudnya Kabupaten Kutai Kartanegara Yang Maju, Mandiri, Sejahtera, Dan Berkeadilan”. Penjabaran makna dari Visi Kabupaten Kutai Kartanegara yaitu, maju, mandiri, sejahtera, dan berkeadilan. 
Smart Regency Kutai Kartanegara ini dianalisis dengan menggunakan metode kerangka kerja Citiasia, karena Citiasia berfokus pada inisiatif untuk mewujudkan kemajuan bangsa (nation advancement). CCSN berkomitmen menjadi yang terdepan dalam membantu klien untuk meningkatkan kapabilitasnya agar Siap Pintar menjadi smart city (smart readiness) dan meningkatkan performa smart city yang direfleksikan pada tingkat kematangan kota (daerah) yang berada pada level optimal (optimized). Melalui pemahaman ini akan mendorong sebuah bangsa untuk maju mencapai tujuan utamanya menjadi sebuah bangsa yang pintar (smart nation).

\section{RUANG LINGKUP}

Ruang lingkup pada penelitian ini dibatasi pada:

1. Enam aspek kota cerdas dalam kerangka kerja Citiasia, yaitu smart governance, smart branding, smart economy, smart living, smart society, dan smart environment.

2. Analisis yang dilakukan mencakup analisis masa depan, analisis kesiapan daerah, dan analisis gap (kesenjangan).

3. Hasil yang diharapkan yaitu dokumen hasil analisis Smart Regency Kutai Kartanegara.

\section{BAHAN DAN METODE}

Konsep Smart City telah didengungkan sejak pertengahan tahun 1980-an. Konsep ini dipicu oleh makin tingginya jumlah penduduk yang mendiami daerah perkotaan. Populasi ini selain membawa manfaat juga mengakibatkan beberapa kerugian dan dampak yang buruk bagi kota yang bersangkutan.

Menurut data dari Badan Pusat Statiktik Republik Indonesia populasi di kawasan perkotaan mencapai $53,3 \%$ di tahun 2015. Faktor ini menjadikan konsep smart city sangat relevan untuk diterapkan di Indonesia, melalui prinsip-prinsip pembangunan yang mengagumkan dan berkelanjutan sehingga menjadi sebuah bangsa yang terdepan (Citiasia Inc., 2016).

\subsection{Citilization}

Citilisasi (Citilization) merupakan sebuah pergeseran baru atas proses transformasi masyarakat ke dalam tiga karakteristik yang terdiri atas modernisasi baru (new modernization), digitalisasi baru (new digitalization), dan civilisasi baru (new civilization). New modernization adalah percepatan akselerasi kemajuan/ kesejahteraan dengan tetap menjaga nilai-nilai tradisi dan identitas sebuah bangsa. New digitalization merupakan pemanfaatan teknologi informasi dan komunikasi untuk memacu kinerja pelayanan pemerintah dan mendorong warga menjadi lebih bertanggung jawab. Sedangkan tujuan akhir dari keduanya adalah tercapainya new civilization, yaitu upaya untuk membangun dan membentuk sebuah peradaban masyarakat sejahtera dan berkebudayaan maju dan terdepan (Citiasia, 2016). Tiga komponen ini disajikan pada gambar 1 .

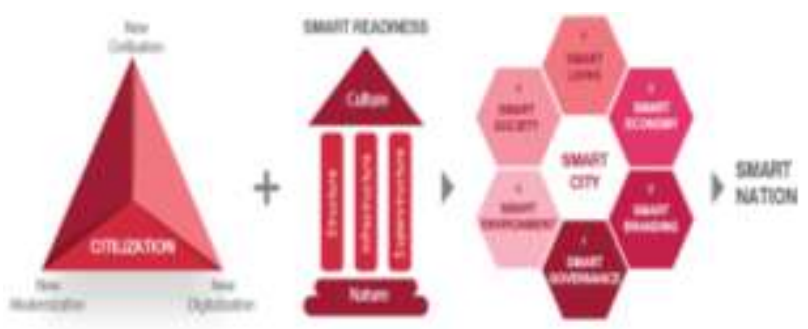

Gambar 1. Smart Nation

\subsection{Enam Elemen Kunci}

Terdapat enam komponen utaman dalam cita-cita Smart City, yaitu smart governance, smart branding, smart economy, smart living, smart society, dan smart environment. Smart Governance merupakan pondasi dasar dari model smart city (smart region). Smart Governance berperan sebagai mesin untuk menggerakkan seluruh elemen smart city lainnya. Smart governance harus diimplementasikan dalam tiga fungsi governance, yaitu kebijakan publik, tata kelola birokrasi, dan pelayanan publik.

Smart branding merupakan elemen terpenting kedua dalam model Smart City. Tujuan dari Smart Branding adalah untuk mempromosikan nilai sebuah kota atau daerah kepada warga, wisatawan, dan pelaku bisnis. Smart branding harus dilakukan terhadap tiga atribut daerah yaitu pariwisata, bisnis dan image (citra daerah).

Smart economy merupakan salah satu tanggung jawab utama sebuah kota (daerah) adalah untuk menciptakan sistem ekonomi yang smart dengan membangun ekosistem industri yang tepat, meningkatkan kesejahteraan warganya, dan menyiapkan infrastruktur transaksi yang mudah dan nyaman. Sedangkan smart living adalah gambaran dari sebuah lingkungan tempat tinggal yang layak bagi penduduknya. Parameter kunci dari smart living adalah adanya harmonisasi dalam kehidupan masyarakat. Harmonisasi tersebut haruslah tercermin dari lingkungan permukiman, fasilitas komersial, dan fasilitas rekreasi untuk masyarakat.

Selain atribut yang telah disebutkan, sebuah kota (daerah) harus mampu untuk menjamin mobilisasi warganya dengan baik dengan sarana transportasi publik dan transportasi pribadi, serta menjamin lancarnya mobilisasi barang dan jasa (logistik). Lebih lanjut lagi, smart living dicerminkan dari kemampuan sebuah kota dan kabupaten menjamin pelayanan kesehatan kepada segenap warganya.

Gambar 2 menyajikan keterkaitan antar komponen tersebut. 


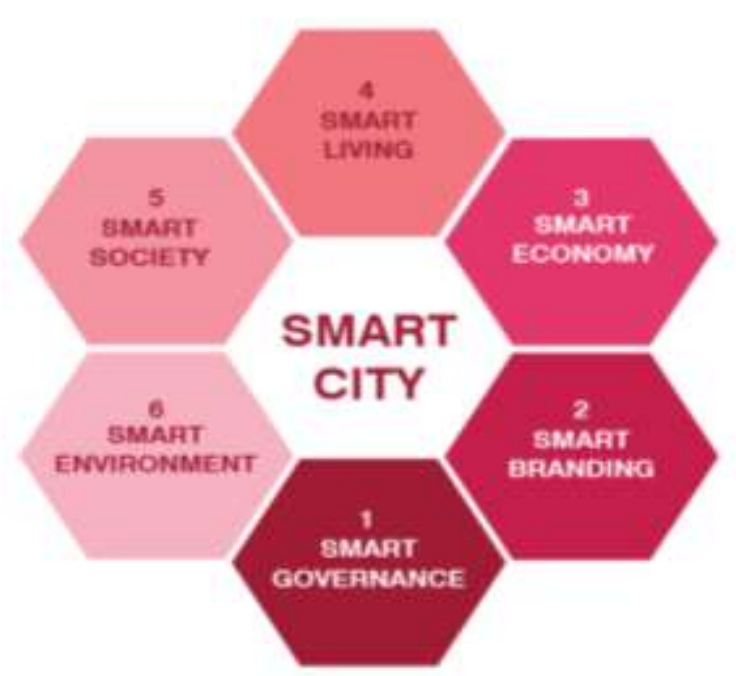

Gambar 2. Enam elemen kunci Smart City (Sikor-Fernandez, 2016)

Smart Society adalah kondisi ideal di mana interaksi masyarakat ada pada kumpulan individu, sosial, dan digital. Setiap individu dalam masyarakat harus diberikan akses terhadap pendidikan yang didukung dengan fasilitas belajar secara digital. Pemerintah memiliki kewajiban untuk menjamin perlindungan terhadap keselamatan jiwa, properti, dan risiko bencana bagi masyarakat.

Smart environment menggambarkan komitmen sebuah kota (daerah) terhadap pelestarian lingkungan, pengelolaan limbah, dan penggunaan energi. Seluruh inisiatif tersebut harus dapat menyokong kehidupan seluruh ekosistem yang ada (Citiasia, 2016).

Dalam visi sistem dan struktur smart cities jangka panjang akan memantau kondisi sendiri dan melakukan perbaikan diri, sesuai kebutuhan. Lingkungan fisik, udara, air, dan ruang hijau di sekitarnya akan dipantau dengan cara yang tidak menonjol untuk kualitas optimal, sehingga menciptakan lingkungan hidup dan kerja yang ditingkatkan yang bersih, efisien, dan aman dan yang menawarkan keunggulan ini dalam kerangka kerja penggunaan paling efektif dari semua sumber daya (Hall, 2014).

\subsection{Analisis Masa Depan}

Pemerintah Kabupaten Kutai Kartanegara dalam RPJMD 2016-2021 menetapkan laju pertumbuhan ekonomi sebesar 4,27\% pada tahun 2021 atau meningkat sebesar $1,5 \%$ dari tahun 2016 dan terkoreksi $1,6 \%$ pada tahun 2021 dari prediksi dalam RPJPD 2005-2025. Sedangkan laju inflasi tahun 2021 diharapkan dapat ditekan pada $6,94 \%$. Untuk mencapai hal tersebut beberapa program kerja dan tujuan pembangunan perekonomian diarahkan pada :

1 Meningkatkan kemandirian fiskal daerah dan kerjasama pembangunan daerah.
2 Mewujudkan percepatan kedaulatan pangan dan revolusi pembangunan pertanian dalam arti luas sebagai daya ungkit pertumbuhan ekonomi daerah.

3 Mewujudkan Kutai Kartanegara sebagai branding pariwisata unggulan di Kalimantan Timur.

4 Mewujudkan ekonomi pedesaan berbasis kelompok dan kewirausahaan yang didukung industri dan perdagangan potensial daerah berbasis keterkaitan dan keterpaduan potensi antar wilayah (Integrated Territorial Development)

5 Meningkatkan pemanfaatan potensi sumber daya alam dan lingkungan hidup.

Pada sektor pembangunan manusia, Indeks Pembangunan Manusia (IPM) pada tahun 2021 dalam PRJMD Kabupaten Kukar diprediksi pada angka 77,21\% atau meningkat sekitar 5,43\% dari capaian IPM di tahun 2015. Untuk mendukung peningkatan angka IPM tersebut, Pemkab Kukar bertujuan mewujudkan sumber daya manusia yang kompeten, sehat, berpendidikan, terampilan, berakhlak dan berperilaku mulia melalui beberapa sasaran seperti meningkatnya daya saing tenaga kerja serta kesempatan dan perluasan kesempatan kerja, meningkatnya aksesibilitas, kualitas dan manajemen pendidikan, meningkatnya penanganan masalah kesejahteraan sosial, meningkatnya akses dan kualitas pelayanan kesehatan, meningkatnya keterpaduan pengentasan kemiskinan antarsektor antarwilayah.

\subsection{Analisis Kesiapan Struktur, Infrastruktur, dan Suprastruktur}

Berikut dijabarkan kesiapan dari KUKAR dalam membangun smart city.

\subsubsection{Kesiapan SDM}

Berdasarkan hasil Proyeksi Penduduk, penduduk Kutai Kartanegara tahun 2016 adalah 735.016 Jiwa yang terdiri atas 385.994 laki-laki dan 349.022 perempuan. Pertumbuhan penduduk Kutai Kartanegara sebesar 2,4\% pada tahun 2016 dan sebagian besar penduduk berada di ibukota Kabupaten Kutai Kartanegara yaitu Kecamatan Tenggarong (16,3\%), dimana hal ini masih jauh dari proyeksi penduduk pada saat 100 kemerdekaan RI, dimana sekitar 75-80\% berada di perkotaan.

Sekitar 99,4\% penduduk berumur 15 tahun ke atas dari keseluruhan penduduk di Kab. Kukar di tahun 2016 telah memiliki kemampuan baca dan tulis huruf latin, 28,93\% diatas umur 5 tahun berstatus bersekolah.

Tenaga pengajar di Kutai Kartanegara untuk semua jenjang pendidikan sudah memadai walaupun pada tingkat SD mencatat beban guru relatif lebih berat dibanding jenjang pendidikan yang lebih tinggi. Rasio murid guru pada Sekolah Dasar (SD) Negeri di bawah Diknas dalam periode 2015/2016 berkisar antara 10-17, artinya seorang guru dalam mengajar harus menghadapi sekitar 10-17 orang murid. Sedangkan beban yang harus dihadapi oleh seorang guru SLTP adalah 2-39 murid, dan 
beban yang harus dihadapi guru SMU adalah 7-44 murid. Pada jenjang Perguruan Tinggi, terdapat 5 PTN/PTS di Kabupaten Kukar mulai dari setingkat Akademi sampai dengan Universitas.

Pembangunan yang merata dapat meningkatkan kesejahteraan masyarakat, sehingga berdampak pada penurunan angka kriminalitas. Angka kriminalitas yang terjadi di Kab. Kukar tahun 2016 sebanyak 763 kasus menurun jika dibandingkan dengan tahun 2015 yang tercatat 1054 kasus. Upaya Pemkab Kukar dalam memelihara kesehatan Sumber Daya Manusia di Kabupaten Kukar tercermin dengan pembangunan berbagai fasilitas kesehatan, seperti Rumah Sakit yang berjumlah 3 RSUD, 32 Puskesmas dan 174 Puskesmas Pembantu yang tersebar di seluruh kecamatan. Tersedia 69 dokter umum dan 43 dokter gigi yang melayani masalah kesehatan penduduk di puskesmas-puskesmas tersebut.

\subsubsection{Kesiapan Birokrasi}

Pemerintahan Kabupaten Kutai Kartanegara didukung dengan 16.126 orang Pegawai Negeri Sipil (PNS) dan 4.799 orang tenaga honorer yang bekerja pada 22 Dinas, 7 Badan dan Dua sekretariat, Tiga RSUD, Inspektorat serta Kesbangpol dengan jumlah 33 Organisasi Perangkat Daerah (OPD). Hak perempuan untuk mendapatkan pekerjaan di pemerintahan sebagai Pegawai Negeri Sipil memiliki kesempatan yang sama dengan pria, gap antargender tidak terlalu signifikan.

Porsi pelaksana tugas atau kegiatan teknis yang umumnya ada pada jenjang diploma ke bawah tersedia dalam jumlah yang cukup banyak jika dibandingkan di level perencana program kerja (jenjang pasca sarjana) atau supervisor (jenjang S1/D4). Berdasarkan umur prosentase terbesar SDM PNS berada pada usia yang relatif produktif, yaitu pada rentang umur 31-50 tahun sebesar 74, 55\% dari total PNS Pemkab Kukar.

\subsubsection{Kesiapan Teknologi Informasi dan Komunikasi}

Hasil survey Sosial Ekonomi Nasional tahun 2016 terdapat sekitar 95,02 \% Penduduk Kabupaten Kukar berumur 5 tahun ke atas mengakses internet dengan menggunakan handphone/smartphone dan 95,37\% akses dilakukan dari rumah. Dari data ini dapat di simpulkan bahwa infrastruktur seluler menjadi tumpuan utama untuk memperoleh atau bertukar informasi dari internet. Mayoritas pengguna internet di Kukar mengakses layanan sosial media, berita dan hiburan, sebagian kecil menggunakan internet untuk mengakses layanan email, mengerjakan tugas sekolah, jual/beli dan layanan lainnya. Jumlah pemilik komputer di rumah sebanyak $22,68 \%$ dari total penduduk Kukar dan dari angka kepemilikan tersebut hanya $16,34 \%$ penduduk yang menggunakan komputernya, sehingga terdapat $6,34 \%$ komputer yang tidak digunakan.

Pemerintah Kabupaten Kukar menunjang kegiatan operasional teknologi informasi dan komunikasi di pemerintahan dengan jaringan komputer lokal menggunakan berbagai media transmisi seperti Fiber Optic, Wireless LAN dan Wire LAN. Selain itu tersedia kawasan-kawasan tertentu yang di-cover oleh layanan free hotspot oleh Diskominfo Kukar. Untuk mengcover wilayah yang cukup luas dan kontur bumi yang berbukit, Pemkab Kukar memiliki 22 Tower yang saling terkoneksi dan diawasi dari Network Operation Center/NOC dan Data Center/DC di Kantor Diskominfo Kukar. Terdapat berbagai Peralatan Jaringan Komputer dan Server untuk berbagai aplikasi layanan (internal/eksternal) di ruangan NOC/DC. Gambar 3 menyajikan topologi optic fiber di kabupaten Kutai Kartanegara.

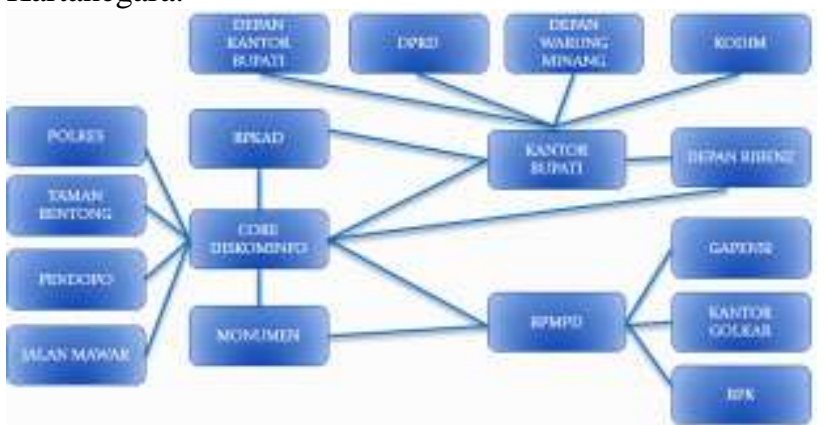

Gambar 3. Topologi Jaringan Serat Optic di Kabupaten Kutai Kartanegara

Dalam proses penilaian Pemeringkatan e-Gov Indonesia (PeGI) yang dilakukan oleh Pemprov Kaltim, pada tabel 1 Kabupaten Kukar mendapatkan skor sebesar 3,2 (dari skala 0 - 4) pada dimensi kebijakan, artinya kebijakan Pemkab Kukar untuk mendukung implementasi TIK dalam business process pemerintahan sudah sangat baik, sedangkan untuk mendukung terbentuknya Smart Regency Kutai Kartanegara, beberapa peraturan telah ditetapkan melalui keputusan DPRD dalam bentuk Perda dan Surat Keputusan Bupati seperti yang dapat dilihat pada tabel 1. Perda No.7 Tahun 2016 tentang RPJMD Kabupaten Kutai Kartanegara telah memuat kebijakan tentang Smart City.

Tabel 1. Skor PeGI Kabupaten Kukar

\begin{tabular}{|l|l|l|}
\hline No. & Nama Dimensi PeGi & Skor \\
\hline 1 & Aplikasi & 2,6 \\
\hline 2 & Infrastruktur & 3,4 \\
\hline 3 & Kebijakan & 3,2 \\
\hline 4 & Kelembagaan & 2,7 \\
\hline 5 & Perencanaan & 2,8 \\
\hline \multicolumn{2}{|c|}{ Rerata } & 2,94 \\
\hline
\end{tabular}

\subsection{Analisis Kesenjangan}

Terdapat berbagai faktor-faktor yang dapat menjadi titik kekuatan, kelemahan, peluang dan ancaman dalam pelaksanaan smart regency di Kabupaten Kukar. Secara umum, kawasan Kutai Kartanegara masih di kenal masyarakat Indonesia sebagai wilayah yang kaya dengan Sumber Daya Alam berupa hasil migas dan 
pertambangan. Secara historis, Kabupaten Kukar terdapat Kerajaan Kutai di kenal sebagai bentuk pemerintahan kerajaan pertama yang tercatat dalam sejarah di Indonesia.

Kondisi Geografis Kukar cukup beragam, mulai dari kawasan pantai, delta sungai, aliran sungai hingga pegunungan, dengan curah hujan yang cukup tinggi sepanjang tahun, hal ini memberikan efek positif untuk pengembangan jenis-jenis usaha di bidang pertanian, peternakan, perikanan dan wisata. Kabupaten Kukar juga berbatasan dengan dua kota yang cukup besar dan padat penduduknya, yaitu Samarinda dan Balikpapan, serta 1 kota berbasis industri yaitu Bontang. Ketiga kota ini memiliki potensi masing-masing yang juga dapat menjadi ancaman bagi Kabupaten Kukar.

\section{PEMBAHASAN}

Kegiatan analisis yang telah dilakukan secara kompleks mulai dari aspek kesiapan masa depan, struktur, infrastruktur dan suprastruktur, serta analisis kesenjangan bermuara pada perumusan strategi pada keenam elemen smart city yang meliputi aspek kekuatan, kelemahan, peluang, dan ancaman.

\subsection{Smart Governance}

\subsubsection{Kekuatan}

Ketersediaan infrastruktur TIK, berupa jaringan serat optik yang menjangkau seluruh OPD di kawasan Ibu Kota Kabupaten dan Tower untuk Jaringan Wireless LAN di 22 titik kecamatan serta memiliki berbagai macam layanan internal pemerintahan dan layanan kepada masyarakat yang telah didukung dengan Aplikasi/Sistem Informasi.

\subsubsection{Kelemahan}

Berbagai Sistem Informasi yang ada di OPD Pemkab Kukar belum terintegrasi, sehingga masih terjadi duplikasi data atau proses.

\subsubsection{Peluang}

Pemerintah menyediakan proses perizinan dengan aplikasi sampai tingkat kecamatan dan seluruh proses gratis kecuali untuk keperluan Ijin Mendirikan Bangunan (IMB). Berbagai aplikasi di tingkat kecamatan dapat dihubungkan dengan memanfaatkan infrastruktur teknologi informasi dan komunikasi.

Pemkab Kukar dapat memanfaatkan Infrastruktur yang ada untuk mengintegrasikan Sistem Informasi yang ada di semua OPD. Data-data pada aplikasi perizinan dapat menggunakan data yang tersedia pada berbagai aplikasi/sistem informasi yang telah digunakan untuk layanan masyarakat atau pemerintahan.

\subsubsection{Ancaman}

Tingginya jumlah kepemilikan beberapa perusahaan pada sektor strategis (energi) di Kabupaten Kukar yang berasal dari investor atau perusahaan dari luar negeri.
Dengan memberikan kemudahan layanan dalam proses perizinan, diharapkan jumlah investor atau perusahaan dalam negeri yang berinvestasi di Kabupaten Kukar akan meningkat. Integrasi Data/Sistem Informasi akan mengurangi duplikasi data dan proses berulang yang dapat terjadi dalam prosedur perizinan.

\subsection{Smart Branding}

\subsubsection{Kekuatan}

Telah ditetapkan Logo dan Jargon Smart Regency Kutai Kartanegara seperti ditunjukkan pada gambar 4 yang akan menjadi simbol gerakan smart regency kabupaten Kukar dengan falsafah luhur menciptakan tata kelola pemerintahan yang mampu membawa kabupaten menjadi daerah yang maju dengan kekuatan TIK.

Pemerintah menyediakan proses perizinan dengan aplikasi sampai tingkat kecamatan dan seluruh proses gratis kecuali untuk Ijin Mendirikan Bangunan.

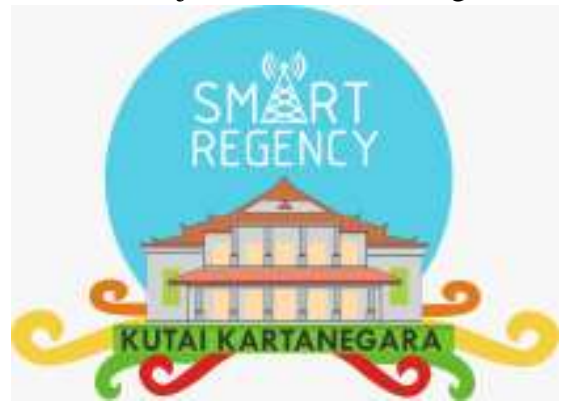

Gambar 5. Logo Smart Regency Kabupaten Kukar

\subsubsection{Kelemahan}

Produk lokal belum punya ciri khas yang seragam serta masih banyak UMKM yang belum berizin dan banyak produk makanan yang belum memiliki label PIRT (Pangan Industri Rumah Tangga).

\subsubsection{Peluang}

1. Terdapat 38 ribu Usaha Mikro, Kecil dan Menengah (UMKM) dan 2500 UMKM yang sudah berizin.

2. Setiap produk lokal dari Kabupaten Kukar akan menyertakan Logo atau Jargon Smart Regency.

3. Strategi yang dilakukan adalah mewajibkan setiap pemohon untuk menyertakan logo dan jargon dalam produknya dalam proses perizinan.

\subsubsection{Ancaman}

1. Produk sejenis dari luar Kab Kukar banyak yang telah memiliki PIRT dan berasal dari UMKM yang memiliki izin.

2. jumlah UMKM yang belum berizin dan jumlah kepemilikan label PIRT.

\subsection{Smart Economy}

Ada kawasan-kawasan yang telah ditetapkan secara legal sebagai kawasan parkir kendaraan. Penetapan ini akan lebih memudahkan dalah proses kontrol dan manajemen pemasukan kas daerah. 


\subsubsection{Kelemahan}

Kelemahan kabupaten dalam hal ini adalah belum adanya aplikasi yang menangani masalah parkir. Sedangkan telah ada beberapa pihak swasta yang menawarkan diri untuk mengelola secara resmi dan saling menguntungkan.

\subsubsection{Peluang}

Telah terjalin kerjasama dengan pihak ketiga dalam pengelolaan parkir yang menunggu untuk dikonsolidasikan.

\subsubsection{Ancaman}

1. Kehilangan potensi PAD, terutama dari pengelolaan parkir yang buruk

2. Kurangnya kesadaran pengguna kendaraan untuk membayar retribusi parkir resmi

3. Kehadiran juru parkir liar yang mempengaruhi pemasukan daerah.

Strategi yang dirumuskan untuk aspek ini adalah menetapkan target bagi hasil dan target pencapaian pemasukan dari hasil pengelolaan parkir, sehingga pihak swasta maupun BUMN dapat menyediakan aplikasi untuk mendukung pengelolaan parkir yang baik, memperbaiki pengelolaan parkir menggunakan sistem parkir dengan dukungan teknologi informasi, menertibkan kendaraan yang parkir dan juru parkir liar, serta mulai menggunakan aplikasi untuk melaporkan kehadiran juru parkir liar dan kendaraan yang tidak mau membayar retribusi parkir.

\subsection{Smart Living}

4.4.1. Kekuatan

1. Terdapat kawasan Pulau Kumala untuk pusat rekreasi warga

2. Memiliki Museum Mulawarman

3. Memiliki kawasan-kawasan wisata alam yang lengkap

4. Tersedianya infrastruktur pendukung di kawasankawasan publik

\subsubsection{Kelemahan}

1. Kawasan Pulau Kumala dan objek wisata lainnya belum dikelola dengan baik

2. Belum ada dukungan TI untuk memudahkan pengunjung

\subsubsection{Peluang}

1. Terdapat kesempatan mengadakan kerjasama pengelolaan dengan pihak ketiga.

2. Menarik pengunjung dari kota-kota sekitar Kab.Kukar seperti Samarinda, Balikpapan dan Bontang

\subsubsection{Ancaman}

1. Ancaman yang dialami oleh kabupaten Kukar adalah maraknya perusakan fasilitas oleh pengunjung tempat-tempat keramaian.

2. Munculnya tempat rekreasi baru di daerah lain yang relatif bisa dijangkau (jarak dan biaya).

Strategi yang dirumuskan untuk aspek ini adalah:

1. Membuka wahana-wahana baru untuk menarik minat pengunjung

2. Meningkatkan jumlah fasilitas publik sehingga angka kunjungan dari wisatawan lokal dan mancanegara dapat meningkat

3. Peningkatan pengelolaan dengan pola kerjasama antara pemerintah dengan pihak swasta

4. Menggunakan TI untuk memudahkan pengunjung pusat rekreasi dan museum mulawarman, misalkan penggunakan $e$-ticket dan $e$-money yang terintegrasi dalam sebuah smart card

5. Menggunakan ketersediaan infrastruktur di kawasan publik untuk membangun sistem keamanan dan pengawasan terpadu.

6. Meningkatkan promosi dan menggali keunggulankeunggulan kompetitif yang dimiliki oleh Kabupaten Kukar.

7. Meningkatkan tata kelola kawasan rekreasi, wisata dan publik terutama dalam hal keamanan dan ketertiban.

8. Mengimplementasikan layanan-layanan berbasis teknologi informasi seperti penggunaan QR Code, Augmented Reality, IP Cam serta menggunakan fasilitas promosi di media sosial.

\subsection{Smart Society}

\subsubsection{Kekuatan}

1. Mayoritas pengguna internet di Kukar mengakses dari rumah dan layanan media sosial yang terbanyak digunakan.

2. Daya beli masyarakat untuk ketersediaan perangkat akses/gawai dan biaya akses/data relatif tinggi.

3. Ada Dinas yang bertanggungjawab sebagai pusat pengelolaan IT di Kabupaten Kukar (Diskominfo)

\subsubsection{Kelemahan}

1. Tidak memiliki forum komunikasi khusus warga Kukar atau wilayah-wilayah tertentu di Kabupaten Kukar (misalkan Tenggarong) untuk bertukar informasi

2. Hanya sedikit yang menggunakan internet untuk kegiatan belajar.

3. Kurang keterlibatan pemerintah dalam media sosial atau forum komunikasi warga.

\subsubsection{Peluang}

Peluang aspek society kabupaten Kukar adalah adanya gedung Pusat Komunitas Kreatif di Sanga-sanga. 


\subsubsection{Ancaman}

1. Hoax atau informasi yang menyesatkan warga.

2. Konten negatif yang masuk melalui internet.

Strategi yang dirumuskan dalam smart society ini adalah:

1. Meningkatkan literasi masyarakat tentang penggunaan Internet secara cerdas.

2. Menggunakan media sosial sebagai forum komunikasi bersama untuk update informasi terkini di kabupaten Kukar.

3. Melalui Diskominfo dapat dilakukan penyaringan konten negatif bekerjasama dengan Kemenkominfo dan provider internet.

4. Membentuk forum-forum online sebagai wadah bertukar informasi.

5. Meningkatkan konten-konten pembelajaran agar dapat digunakan oleh warga Kukar.

6. Meningkatkan keterlibatan pemerintahan dalam media social atau forum online komunikasi warga.

\subsection{Smart Environment}

\subsubsection{Kekuatan}

1. Prosedur dalam perizinan tambang melibatkan Pemkab Kukar untuk proses keluarnya izin.

2. Ketersediaan infrastruktur TIK, berupa jaringan serat optik yang menjangkau seluruh OPD di kawasan ibu kota kabupaten dan tower untuk Jaringan Wireless Local Area Network di 22 titik kecamatan.

\subsubsection{Kelemahan}

1. Belum memiliki sistem peringatan dini akan bahaya banjir.

2. Tidak ada proses monitoring dari pemerintah dan/atau pengawasan masyarakat setempat untuk penggunaan lahan pasca tambang.

\subsubsection{Peluang}

1. Terdapat sumber daya alam migas dan nonmigas yang belum dimanfaatkan dalam jumlah yang banyak dan cukup beragam.

2. Kondisi Geografis dari wilayah pantai hingga pegunungan dan daerah aliran sungai Mahakam dengan curah hujan tinggi dan penyebaran yang merata sepanjang tahun

\subsubsection{Ancaman}

1. Lahan pasca tambang ditinggalkan tanpa pengelolaan untuk proses pemulihan/peralihan menjadi lahan produktif.

2. Curah hujan tahunan tinggi dan daerah aliran sungai Mahakam yang dapat menyebabkan banjir dalam jangka waktu relatif lama dan luasnya kawasan yang tergenang.
Strategi yang dirumuskan dalam mewujudkan smart environment adalah:

1. Memberikan kemudahan layanan dalam proses perizinan namun tetap memperhatikan faktor/kondisi agar lingkungan tidak rusak/tercemar.

2. Menggunakan ketersediaan infrastruktur TIK untuk memantau kondisi geografis agar dapat dimanfaatkan sektor lain (misalkan pertanian dan pariwisata).

3. Melakukan kerjasama dengan pihak yang akan mengelola/ memanfaatkan SDA untuk membuat sistem peringatan dini dan pengawasan.

4. Perlu ada uang jaminan pemulihan lahan pasca tambang pada saat proses perizinan tambang diberikan.

5. Terdapat infrastruktur TI yang dapat dimanfaatkan untuk implementasi IoT atau sistem peringatan dini bahaya banjir.

6. Membangun sistem monitoring/pengawasan lahan tambang

7. Membangun sistem peringatan dini akan bahaya banjir dan mengolah big data cuaca/iklim dari berbagai sumber untuk penanganan banjir

\section{KESIMPULAN}

Penelitian ini meramu dan merumuskan berbagai kebijakan dan program kerja yang merupakan hasil analisis dan kajian mendalam mengenai semua aspek kekuatan, kelemahan, peluang dan tantangan yang dipunyai/dihadapi kabupaten Kutai Kartanegara yang mengacu pada kerangka kerja Citiasia yang berpilar pada enam elemen yaitu pemerintahan, branding, ekonomi, kehidupan, masyarakat dan lingkungan.

\section{SARAN}

Penelitian selanjutnya sebagai penelitian pengembangan dapat menelisik lebih dalam keenam aspek tersebut untuk kemudian dirumuskan master plan sebagai acuan pembangunan smart city untuk kabupaten Kutai Kartanegara.

\section{DAFTAR PUSTAKA}

Citiasia, 2015, Smart Nation: Mastering Nation's Advancement from Smart Readiness to Smart City, Jakarta: 2016.

Hall, R.E., Bowerman, B., Braverman, J., Taylor, J., Todosow, H., Von Wimmersperg, U. The Vision of a Smart City, 2nd International Life Extension Technology Workshop, Paris, 2000.

Sikora-Fernandez D., Stawaz D., The Concept of Smart City in the Theory and Practice of Urban Development Management, Romanian Journal of Regional Science, Vol 10 (1), 2016. 